\title{
Deformação Vertical dos Resíduos Sólidos Urbanos em uma Célula Experimental em Função da Composição Gravimétrica e Volumétrica dos Materiais
}

\author{
Vertical deformation by Gravimetric and \\ Volumetric Composition of Municipal \\ Solid Waste in an Experimental Cell
}

\author{
Márcio Camargo de Meloํㅜ, Rômulo de Medeiros Caribé2, \\ Raliny Mota de Souza Farias², Veruschka Escarião Déssoles Monteiro²
}

\footnotetext{
${ }^{1}$ Universidade Federal de Campina Grande (UFCG), Unidade Acadêmica de Saúde (UAS) e Pós-Graduação de Engenharia Civil e Ambiental (PPGECA/UFCG) - CEP: 58.429-900, Cuité, PB, Brasil.

e-mail: melomc@ufcg.edu.br.

${ }^{2}$ Endereço dos outros autores 2, 3 e 4

e-mail: romulo_dk18@hotmail.com; raliny.mota@gmail.com; veruschkamonteiro@hotmail.com.
}

\begin{abstract}
RESUMO
As deformações verticais em aterros de resíduos de Resíduos Sólidos Urbanos (RSU) são resultados da perda de partes sólidas dos constituintes orgânicos. Conhecer as características de gravimetria e volumetria desses resíduos pode contribuir para o desenvolvimento dos recalques em termos percentuais. O objetivo deste trabalho foi quantificar a composição gravimétrica e volumétrica dos RSU associando-as ao comportamento dos recalques em uma Célula Experimental localizada em município de pequeno porte. A metodologia foi constituída da construção, instrumentação e enchimento da Célula Experimental de RSU, seguidos da caracterização física dos resíduos e monitoramento dos recalques ao longo do tempo. Este estudo mostrou que o RSU da cidade estudada é em sua maior parte constituído de matéria orgânica e plásticos, estes materiais influenciaram diretamente o comportamento dos recalques, característica que está intimamente ligada à composição gravimétrica e volumétrica dos resíduos. Porém, estes fatores não determinam unicamente os deslocamentos verticais devendo ser empregados juntamente com outros parâmetros físico-químicos e microbiológicos como demanda química de oxigênio (DQO), demanda biológica de oxigênio (DBO) e sólidos voláteis.
\end{abstract}

Palavras-chave: Gravimetria, volumetria de resíduos, recalques, RSU

\begin{abstract}
The settlements are a result of the loss of the solid parts of the organic constituents of Municipal Solid Waste (MSW) and the knowledge of gravimetric and volumetric characteristics of these residues may contribute to the development of settlements in percentage terms. The objective of this study was quantifying the gravimetric and volumetric composition of MSW relating it to the behavior of settlements in an experimental cell located in a small city. The methodology consisted of construction, instrumentation and filling of the experimental cell MSW, followed by physical characterization and monitoring of the waste settlements over time. This study showed that MSW of the city studied is mostly composed of organic matter and plastics. These materials influenced directly on the behavior of settlements, a characteristic that is closely linked to gravimetric and volumetric composition of the waste. However, as only these factors do not determine the vertical displacements, other physico-chemical and microbiological parameters of great importance should be also analysed as chemical oxygen demand (COD), biological oxygen demand (BOD) and volatile solids.
\end{abstract}

Keywords: Gravimetry, volumetry of waste, settlements, MSW

\section{INTRODUÇÃO}

A definição de deformação vertical ou recalque pela engenharia geotécnica convencional refere-se à defor- 
mação vertical positiva do terreno proveniente da aplicação de cargas externas ou do seu peso próprio [1]. No caso de aterros de Resíduos Sólidos Urbanos (RSU) estas deformações podem ser definidas como deslocamentos verticais descendentes da superfície do aterro, provocados por cargas externas, como peso próprio dos seus constituintes e da camada de cobertura, compactação, influências meteorológicas e principalmente devido à degradação biológica dos resíduos depositados.

As deformações em Resíduos Sólidos Urbanos são associados a decomposição da matéria orgânica com expulsão de líquidos e gases [2]. Entretanto, estudos da composição gravimétrica e volumétrica dos RSU são relevantes quando se leva em consideração as deformações verticais na massa de resíduos.

A composição gravimétrica e volumétrica é utilizada como um indicador da quantidade que cada tipo de resíduos ocupa em peso e volume nas células de um aterro, direcionando, inclusive, como a gestão destes resíduos deverá ser realizada pelos órgãos públicos [3].

Quando se fala em gravimetria e volumetria de resíduos em aterros de RSU é comum pensar em termos de composição dos resíduos, mas não se associa estes parâmetros as deformações e as decomposições desses materiais. A composição gravimétrica permite identificar o resíduo gerado, sendo a etapa inicial de qualquer definição posterior de gerenciamento que constitui uma informação importante na compreensão do comportamento da massa de resíduos, aterrados ou não, e expressa, em percentual, a presença de cada componente, em relação ao peso total da amostra confinada de resíduos sólidos [4].

VAN MEERTEN et al.[5] cita, entre outros fatores, a composição gravimétrica como um dos principais agentes da degradação da matéria que compõem os resíduos. Pode-se dizer que tanto a composição gravimétrica como volumétrica estão diretamente ligadas aos níveis de recalques, podendo afetar o comportamento mecânico dos resíduos. A caracterização física dos resíduos contribui para o monitoramento ambiental, na compreensão do processo de decomposição da massa de resíduos sólidos aterrados e na estimativa da vida útil da área utilizada para disposição de RSU [4].

O maior contribuinte para que os recalques ocorram é a matéria orgânica degradável presente no interior da massa de resíduos, podendo ser aferida por meio da caracterização física. Em aterro de RSU, principalmente para países em desenvolvimento, a matéria orgânica representa a maior parte de seus constituintes, portanto, é importante definir quanto de fato a quantidade de matéria orgânica pôde contribuir para que ocorra o recalque em termos percentuais. O objetivo deste trabalho foi quantificar a deformação vertical dos resíduos sólidos urbanos em uma célula experimental baseado nas composições gravimétricas e volumétricas do resíduo.

\section{MATERIAIS E MÉTODOS}

\subsection{Construção da célula experimental}

Para o desenvolvimento deste trabalho foi construída uma Célula Experimental ou lisímetro em alvenaria de tijolos manuais (Figura 1), com diâmetro de 2,0m e altura de 3,0m com volume aproximado de $9 \mathrm{~m}^{3}$.

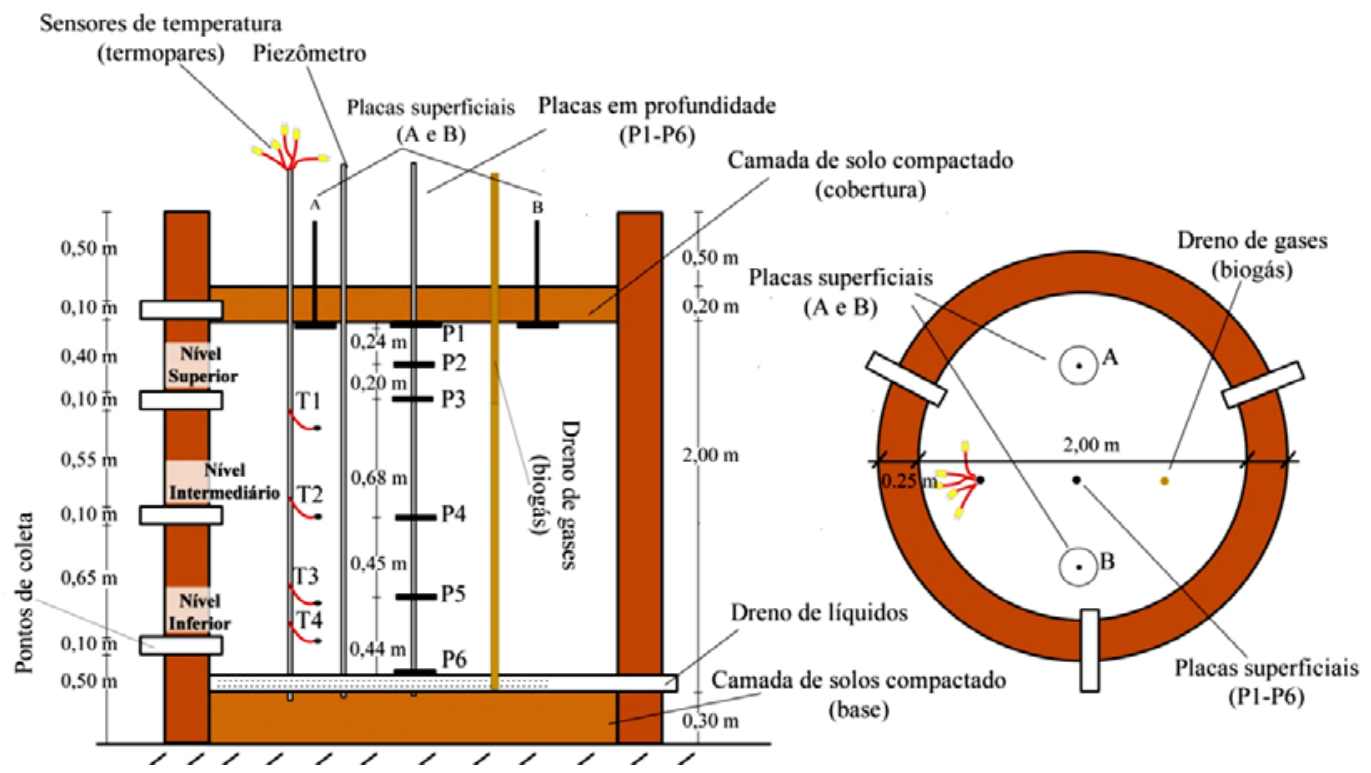

Figura 1: Vista superior e corte vertical da Célula Experimental de RSU. 
A Célula Experimental foi construída no campus universitário do município estudado e instrumentada com medidores de recalques superficiais (Placas A e B) e em profundidade, termopares para a obtenção de dados referentes a temperatura, piezômetros para o monitoramento do nível de líquidos e drenos de gás para quantificar o biogás gerado. Para as camadas de base e cobertura da Célula Experimental foi escolhido um solo com características de baixa permeabilidade $\left(\mathrm{k}=10^{-7} \mathrm{~m} \cdot \mathrm{s}^{-1}\right)$.

\subsection{Coleta, Amostragem de Resíduos e Enchimento da Célula Experimental}

Para a realização da coleta e amostragem utilizou-se o procedimento recomendado pela ABNT [6]. O plano de amostragem foi delimitado dentro do roteiro da coleta de resíduos do município estudado, escolhendo-se o setor que abrangesse três bairros baseados no critério de condição social (classe alta, média e baixa), os dados sociais foram obtidos da Prefeitura Municipal de Campina Grande, PB. A unidade amostral final foi definida a partir dos RSU coletados nesses bairros, obtendo-se uma amostra representativa dos resíduos produzidos na cidade.

Após a coleta dos resíduos provenientes da rota selecionada para a pesquisa, foi realizada a sua homogeneização, baseada na metodologia de LIPOR [7] e adaptado por LEITE [8] e PEREIRA et al. [3] que consistiu no descarregamento dos resíduos sobre área plana para serem homogeneizados e divididos em quatro partes (quarteamento) com auxílio de uma enchedeira. Das quatro partes duas foram descartadas e as outras duas homogeneizadas novamente, formando uma única pilha de resíduos, de onde foram retiradas as parcelas para preenchimento da Célula Experimental e caracterização física dos resíduos.

\subsection{Composição Gravimétrica e Volumétrica dos Resíduos}

Com auxílio de recipientes plásticos, foram retiradas amostras das laterais da base, do centro e do topo da pilha resíduos. Este material foi pesado e em seguida disposto em local previamente preparado para o processo de caracterização gravimétrica e volumétrica dos resíduos soltos e compactados.

O estudo da gravimetria baseou-se na metodologia de LIPOR [7] adaptada por LEITE [8] e PEREIRA et al. [3], onde realizou-se a triagem, pesagem e classificação dos resíduos segundo as subclasses de: plásticos, metais, vidros, compósitos, têxteis sanitários, papel e papelão, matéria orgânica e outros.

A composição volumétrica realizou-se segundo o método de CATAPRETA e SIMÕES [9] e MARIANO et al. [10]. Onde, com o mesmo material utilizado para a composição gravimétrica, foram feitas leituras de volume dos resíduos soltos. Posteriormente, os resíduos foram compactados estaticamente, com o auxílio de um soquete, obtendo-se a composição volumétrica dos resíduos compactados.

\subsection{Monitoramento dos Recalques}

Foram instalados previamente na Célula Experimental medidores de recalque superficial e em profundidade. Para o monitoramento de recalques superficiais foram utilizadas duas placas circulares com diâmetros aproximados de $150 \mathrm{~mm}$, confeccionadas em aço e revestidas com uma película anticorrosiva (Figura 2). Durante o enchimento da célula, ao atingir a altura pré-estabelecida de resíduos, fez-se um nivelamento da camada superficial onde foram instaladas as duas placas de recalques superficiais. Posteriormente, depositou-se uma camada de cobertura de solo compactado de $200 \mathrm{~mm}$.

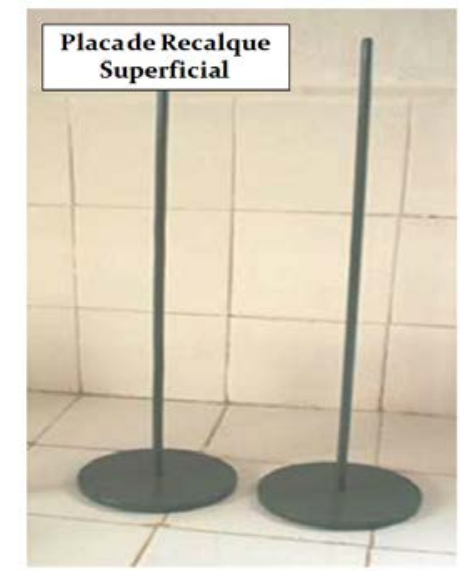

Figura 2: Placas de recalques Superficiais circulares. 
Para se medir os recalques em profundidades foram instaladas previamente placas de recalques em profundidade, que possuem em seu centro um imã, que ao se enviar um torpedo permite a obtenção da leitura, uma vez que este sistema aciona um dispositivo eletrônico e, então, se mede o deslocamento vertical da placa.

As leituras dos recalques superficiais e em profundidade acompanharam os seguintes procedimentos:

- Placas superficiais: duas placas foram posicionadas entre a camada de superfície e a massa de resíduos. Para se medir os recalques superficiais, estendeu-se um fio auxiliar horizontalmente de um lado a outro da abertura da Célula Experimental (topo), mantendo-o nivelado sobre as duas placas superficiais. Mediu-se então a distância vertical do fio até o indicador da posição das Placas.

- Placas em profundidade: foram utilizadas 6 placas magnéticas em diferentes profundidades. As placas magnéticas são providas de um anel com imã permanente e um orifício central destinado à passagem de tubo guia de PVC. A leitura foi realizada introduzindo-se um sensor de campo magnético dentro do tubo guia que identifica a localização da placa magnética e aciona o ohmímetro analógico, modelo FT-1000A, que exibe um sinal por meio de um ponteiro móvel, possibilitando a leitura de recalque (Figura 3 ).



Figura 3: Detalhe da placa magnética em profundidade e do ohmímetro analógico.

\section{RESULTADOS E DISCUSSÕES}

\subsection{Composição gravimétrica e volumétrica}

No que se refere à composição gravimétrica, a Figura 4 apresenta 66\% de matéria orgânica presente no interior da Célula Experimental.

O alto percentual de matéria orgânica na Célula Experimental pode indicar elevada deformação da massa de resíduos resultando em grandes recalques. Esse percentual referencia a importância da composição gravimétrica aplicada à RSU.

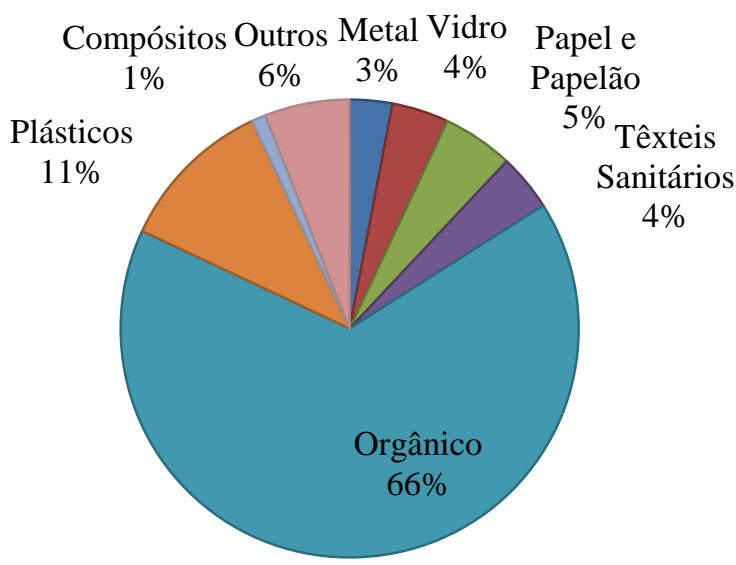

Figura 4: Composição Gravimétrica dos Resíduos. 
Sobre a Figura 4, ainda é possível observar que os plásticos atingiram um valor aproximado de $11 \%$ (percentagem em peso) do total dos resíduos. No caso da composição volumétrica (Figuras 5 e 6 ) observa-se que o teor de plástico é muito superior se comparado à composição gravimétrica uma vez que é um material leve, mas que em grandes quantidades representam volumes excessivos.

Os resultados da composição volumétrica (Figura 5) dos resíduos soltos inferem que as maiores porcentagens dos RSU da cidade estudada são compostos por matéria orgânica putrescível e plástico, com valores aproximados de $38 \%$ e $29 \%$, respectivamente.

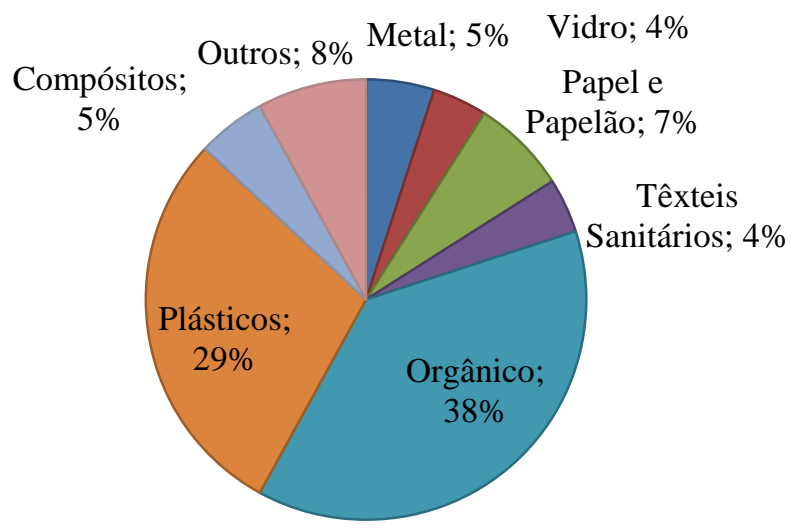

Figura 5: Composição volumétrica dos resíduos sólidos urbanos soltos.

Os componentes plásticos, quando em grandes quantidades, podem segundo FUCALE [11] e GARCEZ [12] ao serem depositados em aterros, dificultar a compactação dos resíduos e prejudicar a decomposição dos materiais putrescíveis, pois criam camadas impermeáveis que afetam as trocas de líquidos e gases gerados no processo de biodegradação da matéria orgânica. Além do mais, bolsões de materiais parcialmente degradados podem ser criados no interior de filmes plásticos dificultando a saída de gases e líquidos pelo sistema de drenagem e, desestruturando o funcionamento mecânico de aterros. Assim, conforme LEITE [8] a triagem dos plásticos é de extrema importância e deve ser valorizada, para que as condições de aterro sejam melhoradas.

A composição volumétrica dos resíduos sólidos compactados foi semelhante ao obtido para os resíduos sólidos soltos neste estudo, alcançando valores aproximados para matéria orgânica putrescível e plásticos de 36\% e 28\%, respectivamente (Figura 6). Esses dados muito próximos podem estar associados às dimensões reduzidas do soquete de compactação e ao seu peso de acordo com a metodologia utilizada. O peso próprio dos resíduos, expresso em unidade de massa específica solta e compactada foram de 0,4 ton. $\mathrm{m}^{-3} \mathrm{e}$ 0,7ton. $\mathrm{m}^{-3}$, respectivamente, esse fator contribuiu para o processo de decomposição da matéria orgânica e redução do volume, favorecendo a ocorrência de recalques.

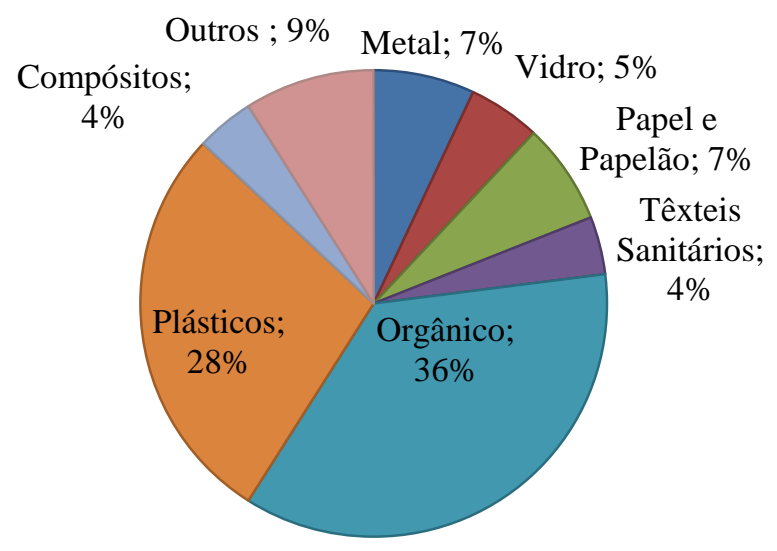

Figura 6: Composição volumétrica dos resíduos sólidos urbanos compactados. 
No caso específico de plásticos, FUCALE [11] relata que estes podem atuar em aterros de RSU como matriz de reforço, sendo a composição dos resíduos semelhante a solos reforçados. Se por um lado os plásticos dificultam a degradação da matéria orgânica por criarem bolsões impermeáveis, por outro lado podem dar maior estabilidade a aterros de RSU. Embora, na Célula Experimental estudada não foram realizados ensaios para determinar o quanto os plásticos representavam em resistência à compressão e tração, pode-se observar que os plásticos dificultavam a retirada de amostras de resíduos demonstrando o seu papel de coesão e agregação dos demais compostos no interior da Célula Experimental. Isto é uma informação muito importante, pois, aterros que são construídos com taludes muito elevados podem tê-los reforçados pela função que os plásticos exercem. MELO [2] relata que os plásticos presentes em uma célula de aterros de RSU por ele estudada dificultaram a drenagem de líquidos e gases por colmatarem os drenos, dificultando, inclusive os recalques, pois ocorreu um acúmulo de líquidos no interior da massa de resíduos.

Especificamente aos resíduos soltos e compactados, mostrados na composição volumétrica, os resultados obtidos para papéis e papelões, compósitos, têxteis sanitários, vidros, metais e outros totalizaram menos de $40 \%$ do volume dos resíduos indicando menor representatividade na caracterização física, porém não menos importante. Mesmo assim, estes materiais, ainda, apresentam valores muito elevados, conforme estudos realizados por CATAPRETA e SIMÕES [9], ALVES [13] e NASCIMENTO [14]. Na verdade não se deveriam encontrar esses materiais em aterros, pois a sua reciclagem é possível, desde que haja programas de gestão que contemple esta atividade associada a incentivos para o setor.

Um ponto muito importante, mas pouco detalhado é justamente em relação ao volume da matéria orgânica ocupado no interior de um aterro de RSU. No caso da Célula Experimental a composição volumétrica da matéria orgânica tanto solta como compactada ocupou 38 e 36\% respectivamente (Figuras 5 e 6). Este dado poderia, inicialmente, levar a conclusão que o recalque devido à degradação da matéria orgânica seria também em torno deste valor.

MCDOUGAL et al. [15] e FIRMO et al. [16] sugerem que nem toda a matéria orgânica é biodegradável e MELO [2] diz que produtos de inibição inerentes à própria degradação da matéria orgânica ou presentes na massa de lixo disposta em aterros podem inibir ou diminuir a atividade metabólica dos microrganismos e, por consequência, a decomposição dos resíduos. Ainda em relação ao recalque outros componentes dispostos no interior da massa de resíduos contribuem com este fenômeno, além do peso da camada de cobertura e o peso dos próprios resíduos [17].

A Tabela 1 apresenta a massa específica solta e compactada de cada tipo de resíduo, para a matéria orgânica foi encontrada uma massa de 0,27 ton. $\mathrm{m}^{-3}$ e 0,4 ton. $\mathrm{m}^{-3}$, respectivamente. Neste caso houve um acréscimo de $25 \%$ no valor de massa específica compactada em relação à solta.

Tabela 1: Valores obtidos por meio da caracterização física dos RSU.

\begin{tabular}{c|cccccc} 
Resíduos & $\begin{array}{c}\text { Composição } \\
\text { Gravimétrica } \\
(\%)\end{array}$ & $\begin{array}{c}\text { Composição } \\
\text { Volumétrica } \\
\text { - R. Solto } \\
(\%)\end{array}$ & $\begin{array}{c}\text { Composição } \\
\text { Volumétrica - R. } \\
\text { Compactado (\%) }\end{array}$ & $\begin{array}{c}\text { Massa } \\
\text { Específica } \\
\text { - Solta } \\
\left.\text { (ton.m }{ }^{-3}\right)\end{array}$ & $\begin{array}{c}\text { Massa } \\
\text { Específica - } \\
\text { Compactada } \\
\left.\text { (ton.m }{ }^{-3}\right)\end{array}$ & $\begin{array}{c}\text { Redução } \\
\text { Volumétrica } \\
(\%)\end{array}$ \\
\hline Plásticos & 11 & 29 & 28 & 0,058 & 0,087 & 66,7 \\
\hline Metais & 3 & 5 & 7 & 0,097 & 0,103 & 94,2 \\
\hline $\begin{array}{c}\text { Texteis } \\
\text { Sanitários }\end{array}$ & 4 & 4 & 4 & 0,146 & 0,209 & 69,9 \\
\hline Outros & 6 & 8 & 9 & 0,107 & 0,138 & 77,5 \\
\hline Vidro & 4 & 4 & 5 & 0,157 & 0,164 & 95,7 \\
\hline Compósitos & 1 & 5 & 4 & 0,044 & 0,08 & 55,0 \\
\hline $\begin{array}{c}\text { Papel e } \\
\text { Papelão }\end{array}$ & 5 & 7 & 7 & 0,122 & 0,169 & 72,2 \\
\hline $\begin{array}{c}\text { Matéria } \\
\text { Orgânica }\end{array}$ & 66 & 38 & 36 & 0,268 & 0,400 & 67,0 \\
\hline
\end{tabular}

Os valores de têxteis sanitários, papéis e papelões são maiores para a massa específica compactada, pois após a sua compactação o volume é reduzido, aumentando o valor da massa específica, o que não acontece para os vidros, pois esse material não possui diferença quantitativa ao se comparar o seu volume solto e compactado. 
A massa específica solta total e compactada total, determinada nesta pesquisa, estão de acordo com a literatura técnica descrita por CAIMOTO e CEPOLLINA [18], LEITE [8], LANDVA e CLARK [19] e GARCEZ [12]. Estes autores relatam ainda que a massa específica compactada de 0,7ton.m- ${ }^{3}$ é um valor excelente para o bom funcionamento mecânico de um aterro. Junqueira [20] diz que para valores em torno de 0,3 ton. $\mathrm{m}^{-3}$ é considerado lixo solto, em torno de 0,5 ton. $\mathrm{m}^{-3}$ lixo no caminhão compactador e mais de 1 ton. $\mathrm{m}^{-3}$ lixo muito compactado no aterro. Os valores dependem de uma série de fatores tais como equipamentos utilizados, teor de umidade, composição dos resíduos etc.

\subsection{Recalques}

Para a análise dos recalques em profundidade foi definido que as placas que os medem estariam em ordem crescente com a profundidade. A Tabela 2 descreve a posição das placas de recalques da camada de cobertura para a camada de base. O critério utilizado para definir a posição das placas de recalques em profundidade foi a proporcionalidade em termos de distância entre as camadas de resíduos bem como os pontos de coleta ou aberturas laterais da Célula Experimental (Figura 1).

Tabela 2: Posição das placas de recalques no interior da Célula Experimental.

\begin{tabular}{l|c}
\hline Placas & $\begin{array}{c}\text { Posição das Placas de Re- } \\
\text { calque (mm) }\end{array}$ \\
\hline Placa a -Superficial & 0 \\
Placa b -Superficial & 0 \\
Placa 1 & 0 \\
Placa 2 & -230 \\
Placa 3 & -430 \\
Placa 4 & -1110 \\
Placa 5 & -1560 \\
Placa 6 & -2000 \\
\hline
\end{tabular}

Durante o período de monitoramento dos recalques em profundidade e ao longo do tempo (Figura 7) verificou-se que as maiores deformações ocorreram na Placa $1(0 \mathrm{~mm})$ situada no centro da Célula Experimental, na camada superior, seguida da placa 2 que fica a 230mm distante da Placa 1 em profundidade. Na Placa 2 foi verificado que ocorreu 370mm de recalques e a Placa $1400 \mathrm{~mm}$ até o final do período de monitoramento da Célula Experimental.

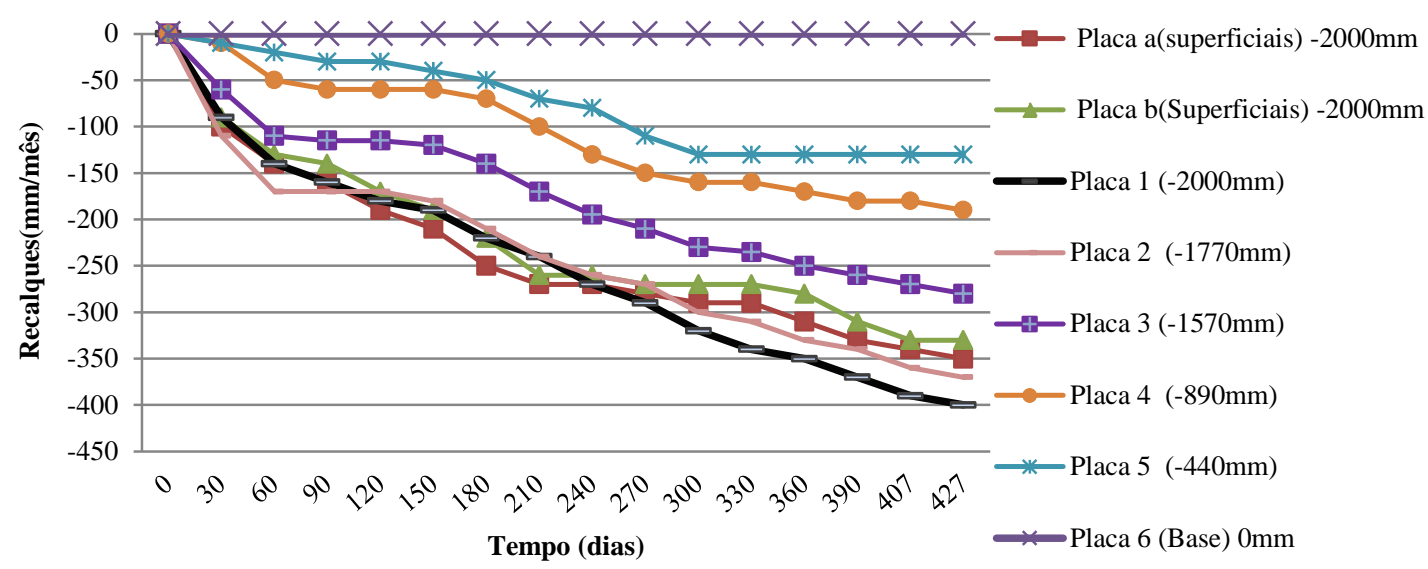

Figura 7: Recalques Superficiais e em Diferentes Profundidades e ao Longo do Tempo.

As Placas Superficiais “a” (situada a esquerda da placa 1) e "b” (situada a direita da placa 1) tiveram 
respectivamente $350 \mathrm{~mm}$ e $330 \mathrm{~mm}$ de recalques. Estes resultados eram previstos já que estas placas estão a $2000 \mathrm{~mm}$ da camada de base.

Como já observado as Placas 1 e 2 tiveram maiores recalques que as Placas Superficiais que estão situadas ao lado, pois na região central da célula há influência das paredes do lisímetro são menores. As paredes da célula interagem com os resíduos que "descolam” e se movem em direção ao centro da Célula, o que implica em maiores recalques na região central. Isto foi verificado por diversos pesquisadores estudando células experimentais em tamanho reduzido e em escalas reais [2, 12, 21].

Os recalques observados na Célula Experimental estudada tiveram um comportamento bastante típico de células em escala real. Assim em profundidades maiores os recalques foram menores. Em células de escala real, MARIANO [22], MELO [2] e MONTEIRO [23] verificaram que os recalques diminuem conforme a profundidade vai aumentando. Este fator ocorre porque os resíduos nas camadas profundas são mais influenciados pela compactação devido ao peso das camadas que estão acima e, a espessura da camada vai diminuindo pela própria posição da placa.

Na Célula Experimental estudada, o valor de 66\% de matéria orgânica inicial no seu interior indica aproximadamente 2,9 toneladas de compostos orgânicos, o que implica em $1330 \mathrm{~mm}$ de altura já que a densidade dos resíduos compactado foi de 0,7 ton. $\mathrm{m}^{-3}$, quando do seu enchimento, entretanto, nem toda a matéria orgânica é biodegradável. Assim, não é possível esperar que toda a matéria orgânica seja consumida e convertida a recalques [1].

A quantidade de matéria orgânica facilmente degradável no interior da massa de resíduos da Célula Experimental é de 0,4ton. $\mathrm{m}^{-3}$, o que indica um total de 1,7ton de compostos orgânicos rapidamente degradáveis. Isto é um dado a ser considerado, pois os recalques iniciais seriam função desta matéria orgânica facilmente ou moderadamente biodegradável e, com o passar do tempo os demais constituintes passariam a contribuir na parcela dos degradáveis, porém muito lentamente.

TCHOBANOGLOUS et al. [24] e MELO [1] relatam que mesmo a parcela rapidamente degradável dos resíduos pode levar um espaço de tempo considerável para ser totalmente consumida, pois no interior do maciço há a presença de compostos agressivos aos microrganismos, às vezes pela própria liberação de substâncias tóxicas do metabolismo dos grupos microbianos, heterogeneidade dos resíduos, diferentes temperaturas e faixas de $\mathrm{pH}$ entre outros fatores [15]. Isto explica porque muitos aterros produzem gases após dezenas de anos de seu fechamento e ainda justificam o seu monitoramento continuo e permanente [22]. O efeito tóxico está intimamente associado à concentração do poluente. Frisa-se que segundo CAMMAROTA [25], no meio ambiente, os poluentes não estão presentes isoladamente sendo comum observar, na avaliação da toxicidade, efeitos inibitórios e sinérgicos causados pela presença de outros compostos. Portanto, não só a degradabilidade dos materiais deve ser avaliada, mas também a presença de inibidores que afetam a taxa de conversão da matéria orgânica em outros compostos.

Se forem analisados os outros constituintes dos RSU no que se refere a caracterização e composição volumétrica encontrados neste estudo é de se esperar que os recalques ocorram por muito tempo, porém, em pequenas quantidades.

As Figuras 8 a 9 apresentam a relação existente entre recalques e a diminuição de sólidos voláteis no tempo pela ação de microrganismos.
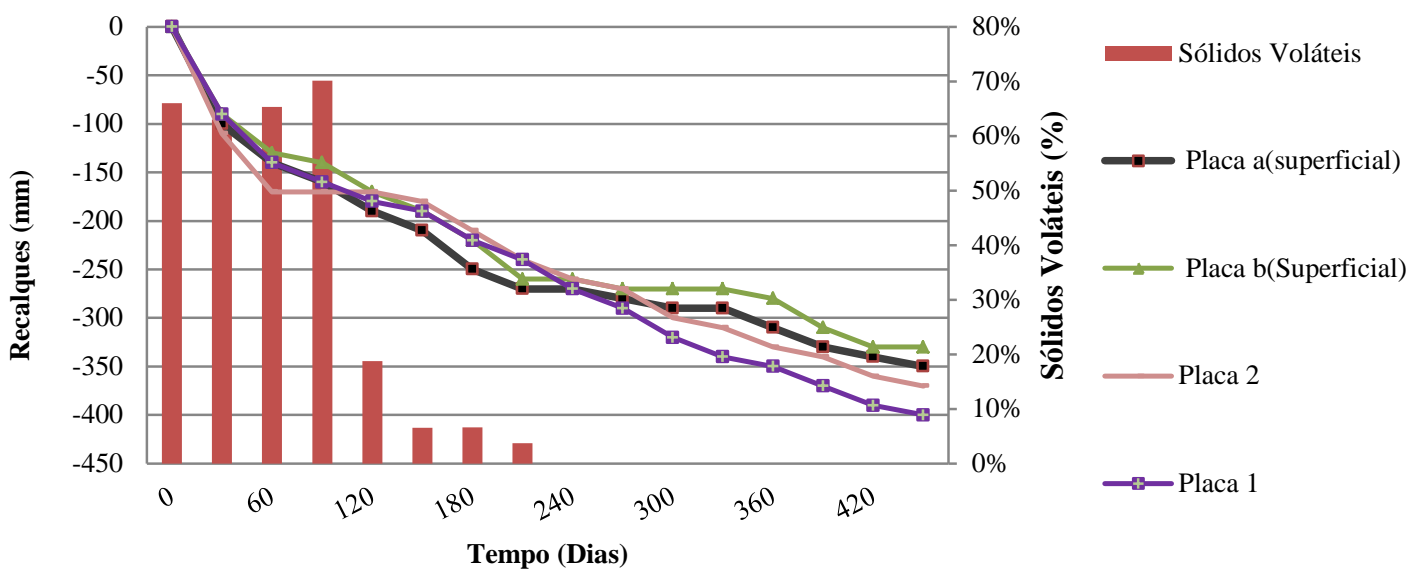

Figura 8: Recalques versus Sólidos Voláteis (Camada Superior). 
Pode-se observar que na camada Superior ( 0 a -1570mm) as deformações verticais distribuídas e observadas nas placas de recalques que as compõe seguem um padrão de deslocamento muito semelhante, e que os maiores recalques ocorreram quando a quantidade de matéria orgânica também era elevada (Figura 8). Entretanto, os recalques continuaram acontecendo mesmo que a matéria orgânica nesta camada já estivesse quase toda depletada após 210 dias. Isto é perfeitamente possível, já que esta camada, por estar mais elevada, sofre recalques devido às deformações que ocorrem nas camadas subsequentes.

No que se referem à camada intermediária da Célula Experimental (-1570mm a -890mm), os recalques tiveram uma melhor correlação visual com o decréscimo da matéria orgânica (sólidos voláteis) no tempo (Figura 9). Os recalques apresentados na Figura 9 são mais acentuados nos primeiros 60 dias de monitoramento enquanto o teor de sólidos voláteis é de 50 a 70\%. Após este período (entre 60 e 120 dias) ocorre a degradação da matéria orgânica com aumento de vazios, porém, não o suficiente para ocorrerem as deformações verticais significativas. Os vazios dos resíduos só irão colapsar quando não suportarem o peso do próprio lixo, mas para que isso ocorra, os vazios, terão de aumentar em tamanho devido à degradação biológica.

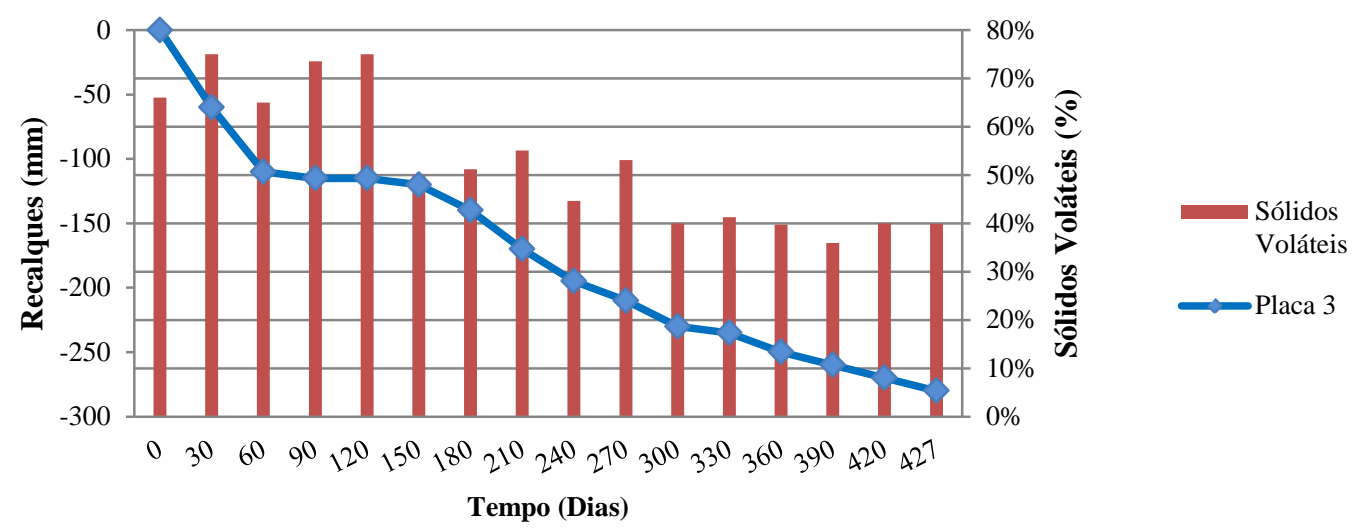

Figura 9: Recalques versus Sólidos voláteis (Camada Intermediária).

Na Figura 10 têm-se os recalques ocorridos na camada inferior (-890mm a 0mm). Esta camada possui as placas 4,5 e 6 . As placas que efetivamente recalcaram foram a 4 e a 5 . Também se pode observar que à medida que a matéria orgânica foi sendo consumida os recalques foram ocorrendo. Os recalques iniciais, a exemplo das placas situadas nas camadas superiores, também foram maiores e diminuíram com o tempo.

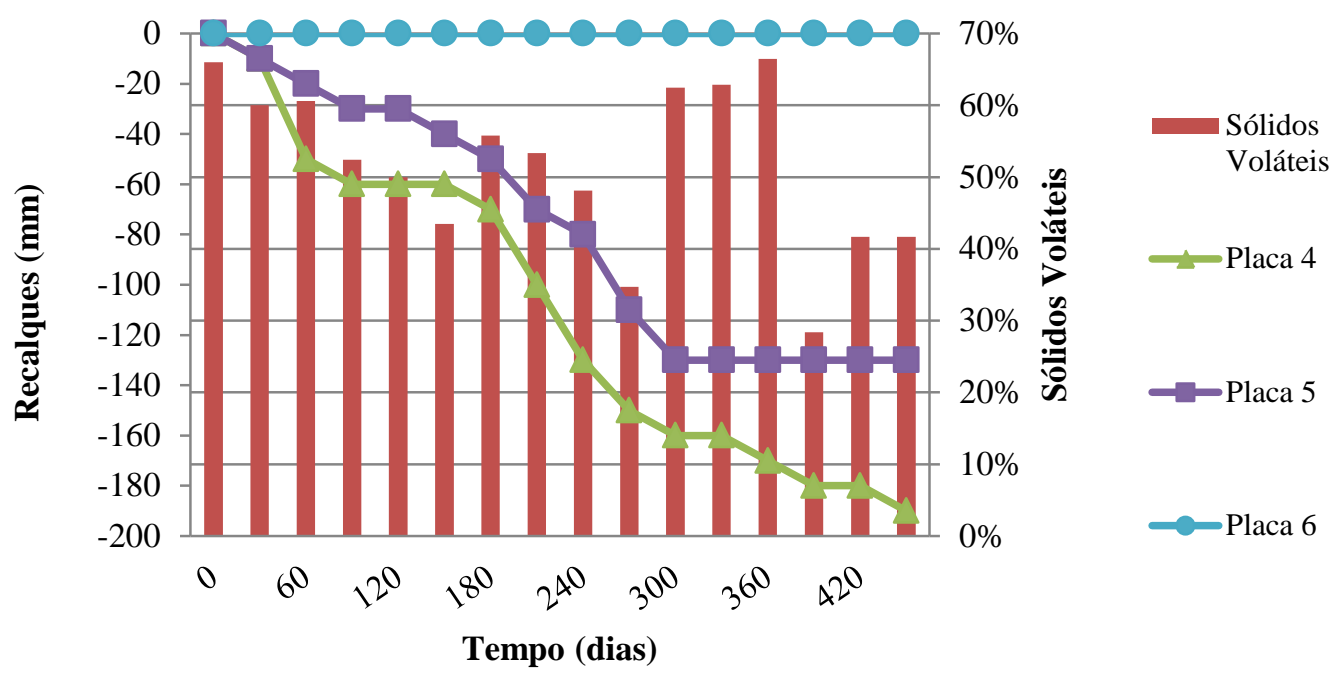

Figura 10: Recalques versus Sólidos voláteis - Camada Inferior. 
Nota-se que nos primeiros 90 dias houve deformações verticais e após este período ocorreu um período de recalque zero, semelhante ao que foi verificado nas camadas superiores. Após este período de não recalque, ocorreu uma outra fase de recalques que correspondeu do dia 120 ao dia 300 seguido, novamente, de recalques zero. Entretanto, na Placa 4, este último período foi de apenas 30 dias e na Placa 5 não se observou mais recalques de 300 dias até o final de monitoramento da Célula Experimental. Na Placa 4 decorridos mais 30 dias (330 dias) iniciou-se os recalques por mais 60 dias (330 a 390 dias) o qual foi procedido por mais 30 dias sem recalques (390 a 420 dias). Depois desta última análise recomeçaram os recalques.

De uma maneira geral, pode-se dizer que a camada que melhor representa, não só os dados de recalques, mas também os demais parâmetros é a camada intermediária, pois esta camada sofre pouco ou nenhuma interferência do ambiente e das camadas adjacentes. A camada superior é a mais influenciada pelo ambiente e isto foi visto nos demais fatores pesquisados.

Deve ser analisado que os recalques não estão intimamente relacionados com o número de microrganismos. No momento em que ocorrem os recalques zero a atividade microbiana é intensa e o aumento de vazios terá de ser, pelos menos teoricamente, maior que no período anterior de recalques zero. Isto leva a outra consideração importante, pois, a diminuição no teor de matéria orgânica não implica necessariamente em recalques.

Outro fator a ser considerado é que quando a Célula Experimental foi sendo preenchida com resíduos o recalques destes resíduos não foi medido, portanto, as camadas inferiores, certamente, obtiveram maiores recalques. Isto, também, ocorre em aterros de escala real e não deve passar despercebido.

De uma maneira geral, o comportamento dos recalques deve ser acompanhado, também, através do monitoramento de outros parâmetros físicos, físico-químicos, químicos e biológicos de grande relevância como Demanda Química de Oxigênio (DQO), Demanda Biológica de Oxigênio (DBO) e sólidos voláteis entre outros.

\section{CONCLUSÕES}

Através deste estudo verificou-se que o comportamento das deformações verticais está intimamente relacionado com a composição gravimétrica e volumétrica dos RSU da Célula Experimental estudada e que a quantidade de matéria orgânica pode indicar o comportamento geral das deformações verticais (recalques). Entretanto, mesmo quando não ocorrem recalques, os chamados períodos de recalques zero, ocorre à degradação da matéria orgânica com aumento de vazios.

Outro fator a ser considerado é que percentagens elevadas de matéria orgânica não se traduzem em recalques, igualmente elevados, pois nem toda a matéria orgânica é biodegradável.

De acordo com os estudos desenvolvidos neste trabalho pôde-se concluir que o conhecimento da composição gravimétrica e volumétrica dos RSU é importante ferramenta na previsão dos recalques, mas outros parâmetros como o monitoramento de aspectos físico-químicos, químicos e biológicos são aliados de igual importância no entendimento do comportamento dos recalques em RSU ao longo do tempo e profundidade.

\section{AGRADECIMENTOS}

Os autores gostariam de agradecer ao Conselho Nacional de Desenvolvimento Científico e Tecnológico (CNPq) pelo apoio financeiro e à Universidade Federal de Campina Grande, onde o trabalho aqui descrito foi realizado.

\section{BIBLIOGRAFIA}

[1] MELO, M.C., Estudo da matéria orgânica nos recalques de resíduos sólidos urbanos aterrados, Tese de D.sc., CCT/UFCG, Campina Grande, PB, Brasil, 2011.

[2] MELO, M.C., Uma análise de recalques associada a biodegradação no aterro de resíduos sólidos da Muribeca, Dissertação de M.sc, CTG/UFPE, Recife, PB, Brasil, 2003.

[3] PEREIRA, F. T. G., LEITE, H. E. A., GARCEZ, L.R., et al., "Composição Gravimétrica dos Resíduos Sólidos Urbanos da Cidade de Campina Grande-PB", In: SINRES-2 Simpósio Nordestino de Resíduos Sólidos, pp 19-21, Campina Grande, PB, Brasil, Mai. 2010.

[4] MELO, V.L.A., JUCÁ, J.F.T., "Estudos de referência para diagnóstico ambiental em aterros de resíduos sólidos”, In: XXVII Congresso Interamericano de Engenharia Sanitária e Ambiental, pp 3-8, Porto Alegre, RS, Brasil, Dez 2000.

[5] VAN MEERTEN, J. J., SELlMEIJER, J. B., PEREBOOM, D.,"Prediction of Landfill Settlement”, In: 
Paper presented at the Sardinia 95 - 5th International Landfill Symposium, Cagliari, Italy, 1995.

[6] ASSOCIAÇÃO BRASILEIRA DE NORMAS TÉCNICAS - ABNT, NBR 10.007, Resíduos Sólidos Amostragem de Resíduos, Rio de Janeiro, 2004.

[7] LIPOR, Serviço Intermunicipalizado de Gestão de Resíduos do Grande Porto, Caderno Técnico, 2000.

[8] LEITE, H.E.A.S. Estudo do comportamento de aterros de RSU em um biorreator em escala experimental na cidade de Campina Grande - Paraíba, Dissertação de M.sc, CTRN/UFCG, Campina Grande, PB, Brasil, 2008.

[9] CATAPRETA, C. A. A., SIMÕES, G. F. "Evaluation of the Relation Between Precipitation and Leachate Flow in an Experimental Sanitary Landfill”, In: XXXI Congresso Interamericano Aidis, pp. 12 -15, Santiago, Chile, Out. 2008.

[10] MARIANO, M.O.H., MACIEL, F.J., FUCALE, S.P., et al. "Composição gravimétrica e volumétrica dos RSU da célula piloto do aterro de resíduos sólidos da Muribeca”, In: $24^{\circ}$ Congresso Brasileiro de Engenharia Sanitária e Ambiental, pp. 2-7, Belo Horizonte, Set. 2007.

[11] FUCALE, S. P., "Resistência em Aterros de Resíduos Sólidos Urbanos.”, In: I Seminário de Tese de D.sc, CTG/UFPE, Recife, PE, Brasil, 2002.

[12] GARCEZ, L. R., Estudo dos componentes tóxicos em um biorreator de resíduos sólidos urbanos da cidade de Campina Grande - PB, Dissertação de M.sc, CTRN/UFCG, Campina Grande/PB, Brasil, 2009.

[13] ALVES, I. R. F. S. Análise Experimental do Potencial de Geração de Biogás em Resíduos Sólidos Urbanos, Dissertação de M.sc, CTG/UFPE, Recife, PE, Brasil, 2008.

[14] NASCIMENTO, J.C.F., Comportamento Mecânico dos Resíduos Sólidos Urbanos, Dissertação de M.sc, EESC/USP, São Paulo, SP, Brasil, 2007.

[15] MCDOUGALL, J.R., PYRAH, I.C., YUEN, S.T.S., et al., "Decomposition and settlement in landfilled waste \& other soil-like materials", Geotechnique, pp. 605-609, v. 9, 54 ed, 2004.

[16] FIRMO, A. L. B., MELO, E. S. R. L., GUIMARÃES, L. J. N. et al., "Avaliação do Potencial de Geração de Biogás dos Componentes dos Resíduos Sólidos Urbanos do Aterro da Muribeca”, In: $3^{\circ}$ Simposio Iberoamericano de Ingeniería de Residuos e $2^{\circ}$ Seminário da Região Nordeste sobre Resíduos Sólidos, pp. 8-10, João Pessoa/PB, Set. 2010.

[17] WALL D.K., ZEISS C. “Municipal Landfill Biodegradation and Settlement”, ASCE J. of Env. Eng., pp. 214-223, v.121, n.3, 1995.

[18] KAIMOTO, L.S.A., CEPOLLINA, M., "Considerações sobre alguns condicionantes e critérios geotécnicos de projeto executivo de aterros sanitários” In: Simpósio Internacional de Qualidade Ambiental, Porto Alegre, RS, Brasil, 16-18 Setembro, 1996.

[19] LANDVA, A. O., CLARK, J. I. Geotechnics of waste fills-Theory and Practice, ASTM STP 1070, pp. 86-103, Philadelphia, 1990.

[20] JUNQUEIRA, F. F., Análise do Comportamento de Resíduos Urbanos e Sistemas Dreno Filtrantes em Diferentes Escalas, com Referência ao Aterro do Jóquei Clube - DF, Tese de D.sc., ENC/FT/UNB, Brasília, DF, 2000.

[21] ALCÂNTARA, P.B., Avaliação da Influência da Composição de Resíduos Sólidos Urbanos no Comportamento de Aterros Simulado, Tese de D.sc, CTG/ UFPE, Recife, PE, Brasil, 2007.

[22] MARIANO, M. O. H. Estudo dos Recalques no Aterro da Muribeca, Dissertação Msc, CTG/UFPE, Recife, PE, Brasil, 1999.

[23] MONTEIRO, V.E.D., Análises Físicas, Químicas e Biológicas no Estudo do Comportamento do Aterro da Muribeca, Tese de D.sc., CTG/UFPE, Recife, PE, Brasil, 2003.

[24] TCHOBANOGLOUS, G.,THEISEN, H., VIGIL, S. A. Integrated solid waste management, Engineering principles and management issues, New York, EUA, 1993.

[25] CAMMAROTA, M. C. Curso de tratamento biológico de efluentes, Escola de Química/UFRJ, Rio de Janeiro, RJ, Brasil, 2003. 